\title{
Research on the Hybrid Teaching Model in Computer Courses Based on the OBE Concept
}

\author{
Juan Li* \\ School of Computer Science and Engineering, Wuhan Institute of Technology, Wuhan 430074, Hubei Province, China \\ *Corresponding author: Juan Li, juanli2018@wit.edu.cn

\begin{abstract}
At present, the demand for high-tech practical talents in China is increasing. It is particularly important to concoct a teaching model, which adapts to the national new engineering construction strategy based on the current situation of college computer learning and teaching, for computer courses. In view of the existing problems in the teaching of computer courses, there is a transformation from process-oriented to result-oriented in this study, combining online information teaching and offline classroom teaching as well as proposing a hybrid teaching model based on the OBE concept. This article assumes the public basic computer course for engineering majors as an example to explain and summarize the hybrid teaching model based on the OBE concept from the whole teaching process.
\end{abstract}

Keywords: OBE concept; Computer courses; Hybrid teaching; Online and offline

Publication date: December 2021; Online publication: December 23, 2021

\section{Introduction}

With the rapid development of the computer industry, computer technology has been widely used in various fields. Universities in the country are paying more attention to the training of high-tech practical talents. In this context, the training of college students across the country requires more and more computer courses. With limited time, it is a problem in the process of students mastering professional knowledge and skills in computer courses as well as have certain core competitiveness.

At present, most colleges and universities still focus on classroom teaching in computer courses and the traditional teaching model is supplemented by practical teaching. The main characteristics of curriculum teaching are as follows: teachers would conduct systematic knowledge teaching based on textbooks in classrooms, while students passively accept knowledge and complete certain exercises after class to fortify their knowledge. In addition, certain practical classrooms are supplemented according to the characteristics of the course, such as programming language and other courses. Teachers would usually arrange experimental classes to develop students' computer programming skills ${ }^{[1]}$. This kind of teaching model has a single teaching method; it does not meet the diverse needs of students and has a simple assessment method. It can no longer meet the high requirements of modern society for the training of computer students. As a highly practical field, the teaching of computer courses needs to be designed in accordance with the characteristics of the subject ${ }^{[2]}$. In the current information age, the construction of an online teaching platform provides powerful means for the improvement of traditional teaching models. One of the urgent issues to be solved in college computer courses is how to fully combine traditional classroom teaching methods with novel online teaching platforms, complement each other, and propose a more effective blended teaching model to improve classroom teaching efficiency and students' learning quality.

Based on this, this study proposes a hybrid teaching method based on the OBE concept that is suitable for public basic computer courses. This method is result-oriented, combining online and offline teaching 
resources and designing related teaching activities as well as a hybrid classroom teaching process around three stages - pre-class, in-class, and after-class. For practical courses, in combination with multimedia, information-based teaching resources, and platforms, a hybrid practical teaching process centered on application cases has been proposed.

\section{Teaching status of computer courses}

Based on the basic teaching requirements of the education steering committee of colleges and universities, along with different professional characteristics and different teaching goals, the current college computer curriculum content can be divided into several types.

(1) Public basic courses for non-computer majors. It is an introductory computer course for freshmen. It focuses on cultivating computational thinking as well as thinking methods and basic skills in solving and dealing with practical problems using computers. Represented by courses such as computer fundamentals for college students, computational thinking, and programming foundation.

(2) Basic courses for computer majors. The basic professional courses for computer majors are mainly based on computer operating systems, composition principles, computer networks, databases, software theory, etc., which are suitable for the training of all computer majors and focus on cultivating students' basic skills and qualities.

(3) Professional courses for students majoring in computer science. It belongs to the " $1+X$ " system courses, involving multiple different computer expertise, with strong theoretical and more specific application.

Students have different majors, foundations, course goals, and teaching emphasis. If the same teaching model is used, the effect may not be ideal. This article takes public basic computer courses for non-computer majors as an example. From the perspective of its existing teaching model, there are several problems ${ }^{[3]}$.

First of all, the teaching form is single. At this stage, most computer courses use the traditional teachercentered teaching method, mainly through classroom lectures, but with a some experimental teaching. Usually in classroom teaching, teachers would conduct systematic knowledge teaching based on textbooks, and students would passively accept new knowledge and complete certain exercises after classes to fortify their knowledge. During practical lessons, teachers would still refer to textbooks, explain the course, and then ask the students to program and complete the case by themselves while referring to the practical case. The students would then obtain the results and finally write out the experimental report. At the end of the semester, the students' test scores are used as a standard to measure the quality of teaching and the achievement of training goals. Especially in public basic courses for engineering majors, the number of students in the class is large, the pace of the class is relatively fast, and the sense of self-identity of noncomputer majors is low. A single teaching model is bound to cause students to feel worse.

Secondly, the teaching equipment is below par. At this stage, whether they are public basic courses, basic courses, or professional courses, computer courses are inseparable from experimental teaching. However, the laboratory hardware configuration is poor, the software installation is flawed, the sound amplification equipment is incomplete, and some computers are not even fully equipped. These problems directly or indirectly restrict the smooth progress of experimental teaching activities.

Finally, the teaching content is not applicable to the industry. The training offered by these computer courses is backdated, and the teaching content is not organically integrated with professional characteristics. It is manifested in the blind selection of teaching materials, the lack of professional characteristics in the formulation of teaching goals, and the lack of field application in the teaching content. This directly leads to the lack of professionalism among the trained students and the inability of their technical skills to adapt 
to the needs of society.

\section{OBE theory}

OBE (outcome-based education) is an outcome-oriented education proposed by Spady in $1981^{[4]}$. It is also known as ability-oriented education, goal-oriented education, or demand-oriented education. It means that the goal of the teaching design and teaching implementation is the final results achieved by the students through education. The core idea of OBE is to train students in a targeted manner according to the needs of social development for talents and the students' personal abilities as well as achievements that they wish to achieve to reverse the design of the teaching process.

In the course design based on the OBE concept, it is necessary to focus on a series of questions, such as "What kind of learning results do students need to achieve?", "Why should students achieve these results?", "How to help students achieve these learning results?", and "How to know and verify whether students have achieved these learning outcomes?", in order to design training programs, teaching processes, etc. Outcome-oriented education advocates a reverse design principle. The use of this principle can make up for the inadequacy of the traditional teacher-centered classroom teaching and pay more attention to the skills that students can acquire upon graduation. In recent years, with the rapid development of the computer industry, computer education is different from traditional subjects, such as mathematics, physics, and chemistry. Schools should pay more attention to application-oriented teaching and focus on training to meet the society's demand for technical talents. However, in the actual teaching process, most teachers still adopt the traditional teacher-centered teaching, and the curriculum teaching is still based on classroom teaching, neglecting the cultivation of students' ability to learn independently and explore new knowledge. This single education model does not combine the characteristics of computer science and can no longer meet the current society's requirements for applied technical talents. It is imperative to explore new teaching models based on the OBE concept and further improve the quality of computer science teaching.

\section{Application of hybrid teaching}

With the rise of online teaching methods, such as MOOC platforms ${ }^{[3]}$, SPOC platforms, and micro-courses, higher education teaching models have ushered in a new round of reforms. Among them, the MOOC platform is a large-scale open online teaching platform. It integrates a variety of online digital resources to form a wealth of curriculum resources. It is suitable for pre-class preparation. It has a wide audience and a large student population. On the other hand, the SPOC platform is a small-scale private online course that can be combined with offline classrooms to provide students with customized and personalized services. Micro-classes focus on a certain knowledge or skill point, with condensed content and prominent themes, which can be used as curriculum resources to assist teaching. All the three teaching methods use online teaching methods and have their own advantages as well as disadvantages.

This study takes the basic computer course of Computational Thinking and Programming Fundamentals for engineering students as an example. Using Chaoxing Learning Platform and Xuexi Tong Platform as carriers, online teaching methods are combined with traditional offline classroom teaching. Focusing on the three stages of teaching links - before class, during class, and after class, a hybrid teaching model based on the OBE concept has been proposed. The hybrid teaching process is shown in Figure 1, where the rectangular boxes represent teaching resources, while the arc rectangles represent teaching activities.

\subsection{Preparation stage}

In the pre-class preparation stage, teachers need to design and formulate a preview task list based on the 
classroom content and publish it in Chaoxing teaching resources; then, they would need to upload relevant learning videos or resources on Chaoxing Learning Platform for students to download them. Students need to $\log$ in to Xue Xi Tong application through a mobile client, check the preview task list, use the learning resources provided by their teachers to learn independently, complete the preparation work questions, and submit them to their teachers for review in time. In this process, learning feedbacks and communication should be conducted in a timely manner.

In the offline preparatory stage, students need to use textbooks and other extracurricular reading materials to learn the content of the course by themselves, communicate, and ask questions in real time through the application.

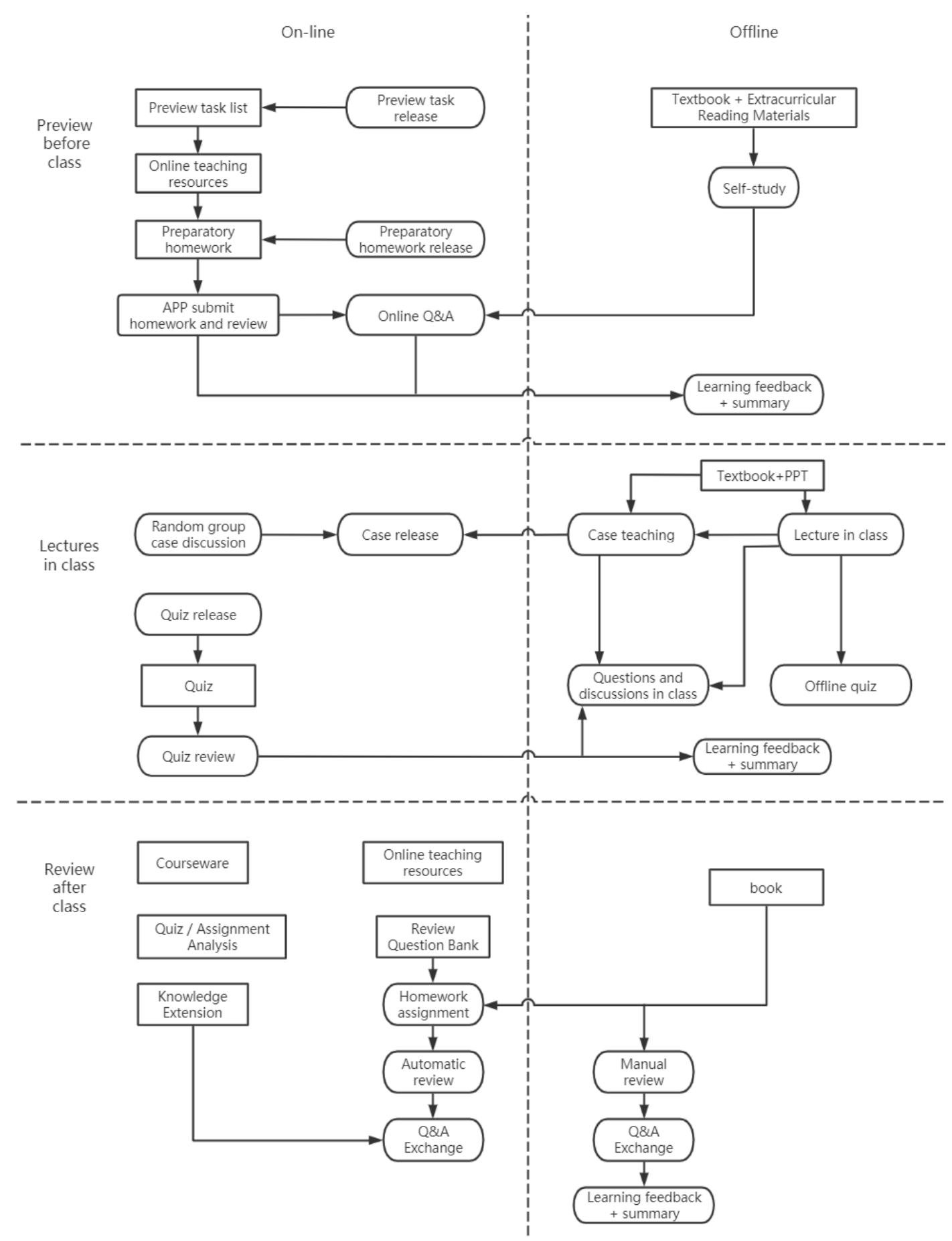

Figure 1. Flow chart of the hybrid teaching model based on the OBE concept 
By refining the teaching content, this kind of online and offline pre-class preparation method, on the one hand, is subdivided into multiple knowledge points, so that students can use their free time to watch and learn; on the other hand, through real-time recording of students' preview situation, teachers are able to gauge the students' preview situation, so as to facilitate targeted teaching in classrooms, thus improving the efficiency of classroom teaching.

\subsection{In-class teaching stage}

In the in-class teaching stage, compared with the traditional teacher-oriented teaching method, the online and offline hybrid teaching method has made the following improvements: (1) during classroom lectures, case teaching links are provided; teachers would publish online classroom cases, and students would then carry out group discussions in classrooms; in-class questions and discussions are carried out to improve the efficiency of the classroom; (2) supplementary teaching methods such as online quizzes are used; students would answer those questions and submit them to a system, which would automatically review and report the results in time; this would help teachers grasp their students' learning dynamics and further improve in targeted teaching; (3) online and offline methods are used in combination to effectively provide feedback on learning, make timely corrections, and guide students to learn, thus achieving twice the result with half the effort.

\subsection{Review stage}

In the review stage after class, a hybrid review method combining online and offline is also adopted. Teachers would upload relevant courseware, online teaching resources, tests and homework analyses, extended reading resources, and question banks on the Xue Xi Tong application in advance. The questions would be automatically extracted from the question banks to form homework exercises, and these exercises would be reviewed automatically upon publishing. Online Q\&A would be carried out to answer the questions. On the other hand, exercises from textbooks would be arranged as exercises in the form of offline homework by the teachers. Having completed the homework, the teachers would manually review and answer the students' questions. Finally, the students would summarize and give feedback to their teachers.

\section{Conclusion}

For students who are not majoring in computer science, the cultivation of computer thinking should become the leading direction of their education. The teaching of basic courses of computational thinking and programming should be under the premise of popularizing basic computer content, weaken the teaching process of theoretical knowledge, and focus on the guidance and cultivation of students' computational thinking ability. Through the cultivation of students' thinking ability, their ability to face practical problems and apply computer thinking to solve problems can be improved.

This article focuses on the existence of such courses in the teaching process, such as the single teaching model, as well as explores and tries to adopt a hybrid teaching model based on the OBE concept, which is a result-oriented concept, based on social needs, with targeted training, using offline classroom teaching in combination with online information teaching to actively guide students' subjective initiative, improve their learning efficiency, as well as achieve the expected results and the teaching goals.

\section{Funding}

This study was supported by the 2020 Ministry of Education Emerging Engineering Research and Practice Project - Research on "Artificial Intelligence +" Specialty Integration Construction and Innovative Talent Cultivation Based on Emerging Engineering Education (Project Number: E-RGZN20201030). 


\section{Disclosure statement}

The author declares that there is no conflict of interest.

\section{Author contributions}

The author, Juan Li, conceived the idea of the study, performed the experiments, analyzed the data, and wrote the paper.

\section{References}

[1] Du Y, Zhu X, Zhang K, 2017, The Reform of Computer Public Course Teaching in the Background of "Flip Classroom" in MOOC Background. Computer Engineering \& Software, 38(08): 84-87.

[2] Dong Z, Xu J, Jin G, et al., 2018, Analysis and Exploration of Teaching Reform Path of Computer Basic Course. Light Industry Science and Technology, 37(03): 150-151.

[3] Mu Z, Dong B, 2014, Exploration of Blended Learning Mode Based on MOOC - Taking Coursera Platform for Example. Modern Educational Technology, 24(5): 73-80.

[4] Ge K, Fan G, Zhou H, et al., 2020, Teaching Practice and Exploration of "Calculation Method" Based on OBE Engineering Education Mode. Light Industry Science and Technology, 36(11): 125-126. 